\title{
Extreme Learning Assistants: Students' Perceptions of Their Undergraduate Laboratory Instructors
}

\author{
Aaron J. Grabow, Ian D. Beatty and William J. Gerace \\ Department of Physics \& Astronomy, University of North Carolina at Greensboro, \\ PO Box 26170, Greensboro NC 26170
}

\begin{abstract}
Several schools have implemented "Learning Assistant" (LA) programs, in which upper-class undergraduates serve as teaching assistants in introductory courses. At UNCG, LAs are given an unusual degree of freedom. Working in teams, they serve as the primary instructors for lab sections of the two introductory calculus-based physics courses. They co-design the lab curriculum with the professor of the lecture section, conduct all lab classes, and grade all student work. In order to investigate how students taking the lab reacted to having undergraduates as lab instructors, we gave and analyzed a short anonymous Likert-type survey probing students' opinions at the end of the first course. We found that overall, most students reacted favorably. They found the LAs' content knowledge and pedagogic skills to be adequate, and saw some benefit to having undergraduates rather than faculty to interact with. They also perceived that the responded to questions with guiding questions rather than authoritative answers.
\end{abstract}

Keywords: Learning Assistants, Teaching Assistants, Undergraduate Instructors, Laboratory Instruction. PACS: 01.40.Fk, 01.50.Qb, 01.40.gb, 01.40.jc.

\section{INTRODUCTION}

At several universities across the US, science departments have implemented "Learning Assistant" (LA) programs, in which upper-class majors serve as teaching assistants for introductory courses. Often, LAs facilitate structured, collaborative group work by students in the course $[1,2,3]$. The term "Learning Assistant program" implies more than just the use of undergraduates as teaching assistants; LA programs include explicit instruction for the LAs in research-based pedagogical strategies and tactics, and are aimed at recruiting students into a teaching profession [4].

In Spring 2010, the Department of Physics and Astronomy at the University of North Carolina at Greensboro (UNCG) instituted an LA program in which upper-class physics majors act as the primary instructors of the laboratory sections attached to our two-semester calculus-based physics sequence. We call this program "extreme" because the LAs assume an unusual degree of responsibility, handling all in-class instruction and contributing heavily to the instructional design and planning of the course.

Each semester, the faculty member teaching the lecture section (either the second or third author of this paper) provides the overall lab section structure, including the high-level learning objectives, the grading system, and the general outline of topics and experiments. He then supervises a team of LAs as they flesh out and implement that structure. The faculty member and LAs meet together a few times before the start of the term and once or twice each week during it. During these meetings, they collaboratively discuss and evolve the overall plan for the semester, reflect upon prior labs, and strategize upcoming ones. The LA team develops the details of each lab, including apparatus selection, development of experiment specifics and instructions, preparation of handouts, and planning of the specific sequence of events. LAs also team-teach each of the two lab sections, with the faculty member dropping in occasionally to observe.

At the start of the semester's first lab class, the faculty supervisor frames for students the lab course and the use of undergraduate instructors. He describes how the lab course articulates with the lecture, briefly explains the LA program, and introduces the LAs. He assures students that these LAs are highly qualified upper-class physics majors who have done well when they themselves were students in this course, and who are working closely with the faculty member behind the scenes to ensure a high-quality learning experience. $\mathrm{He}$ also emphasizes that students are always welcome to come to him with any questions or concerns regarding the lab course and how it is conducted. After answering any questions students might raise, he turns the class over to the LAs and departs.

Each year, the LA team typically consists of four students: two veterans from the prior year's team and two rookies recruited by invitation from among the students who took the course the prior year. One veteran and one rookie generally take responsibility for each lab section meeting. The others often attend, to observe and to provide additional interaction with lab groups. Over two semesters, each rookie takes on an increasing 


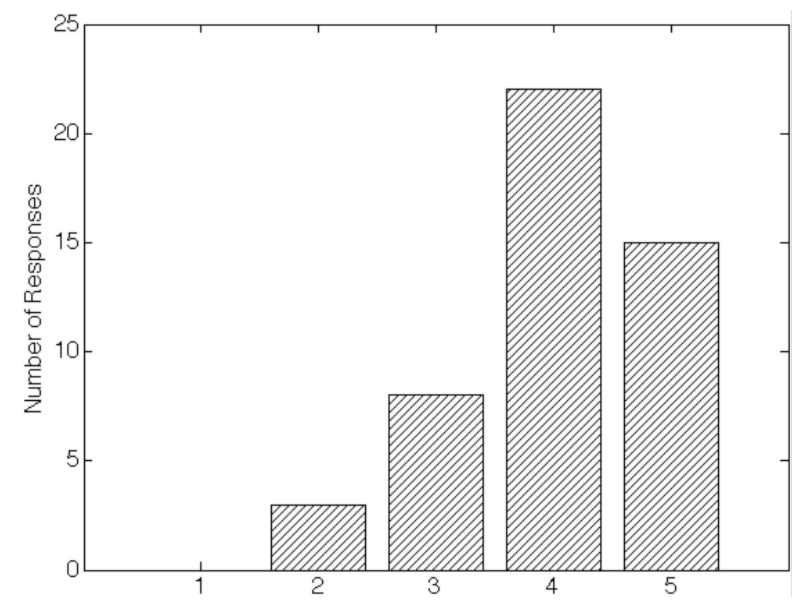

FIGURE 1. Histogram of responses to the prompt "The lab instructors displayed a thorough understanding of the lab material."

share of the responsibility, at a rate dictated by his or her growing level of confidence.

This program meets our two criteria for being a "learning assistant" program. It explicitly introduces the participants to research-based pedagogical theory and practice during the reflection-and-planning. It has been designed to provide participants with as authentic a teaching experience as possible, in the hopes that this will increase their understanding of and interest in a possible teaching career. (A companion paper in this proceedings volume explores the impact of the program upon LA participants [5].)

A serious danger of such an "extreme" LA program is that students taking the course will, rightly or wrongly, perceive their undergraduate lab instructors as under-qualified or inferior to a graduate or faculty instructor. This paper presents the results of a very preliminary investigation into students' perceptions of their LAs' competence and adequacy as lab instructors.

\section{DATA COLLECTION}

At UNCG, General Physics I with Calculus ("Physics I") is taught every spring, and General Physics II with Calculus ("Physics II") every fall. This study was conducted at the end of the Spring 2013 semester, with students just completing Physics I and having experienced only one semester of LA-taught physics labs. Our third author (Gerace) was the Physics I lecture instructor and LAs supervisor that semester. Our first author, Grabow, served as a LA in this program from Fall 2011 through Spring 2013.

During the Physics I final exam period, students were given a short anonymous questionnaire about their experience with undergraduate LAs. Of the 55 students enrolled, 51 were present, of whom 47 completed and returned the questionnaire. The questionnaire consisted of seven Likert-type scales soliciting

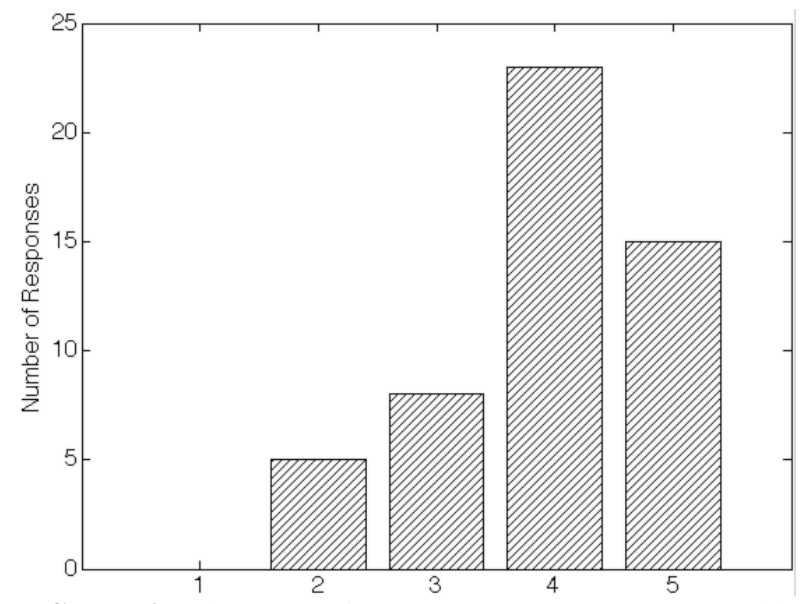

FIGURE 2. Histogram of responses to the prompt "The lab instructors displayed a thorough understanding of the course material."

agreement or disagreement with various statements about the lab instructors' efficacy, and an open-ended response box inviting "any additional thoughts or comments about the lab instructors." For all seven scales, students were asked to select "strongly disagree" (1), "disagree", (2), "neutral" (3), "agree" (4), or "strongly agree" (5).

\section{RESULTS}

The first two questionnaire prompts probed students' perceptions of the adequacy of the LAs' topical knowledge. Prompt 1 was "The lab instructors displayed a thorough understanding of the lab material," and prompt 2 was "The lab instructors displayed a thorough understanding of the course material." Figures 1 and 2 display histograms of students' responses to these prompts. Whether or not respondents distinguished between these very similar questions, the histogram shapes indicate that most students were generally satisfied with the LAs' content knowledge.

A fundamental, guiding pedagogical principle stressed to LAs was that they should serve as facilitators rather than authorities, helping students learn to answer their own questions rather than simply providing answers. Prompt 3 probed the degree to which this occurred, at least as perceived by the students: "When answering a question the lab instructors guided me to the thought process needed to answer the question rather then telling me the answer." Figure 3 shows the responses to this prompt, indicating strongly that LAs were attempting to follow this principle.

This begs the question of whether the LAs could follow it effectively. Prompt 4 probed this with, "The lab instructors were able to clear up points of confusion when asked." Figure 4 shows responses to this prompt, indicating that students were generally, if not always, satisfied that LAs could provide useful assistance- 


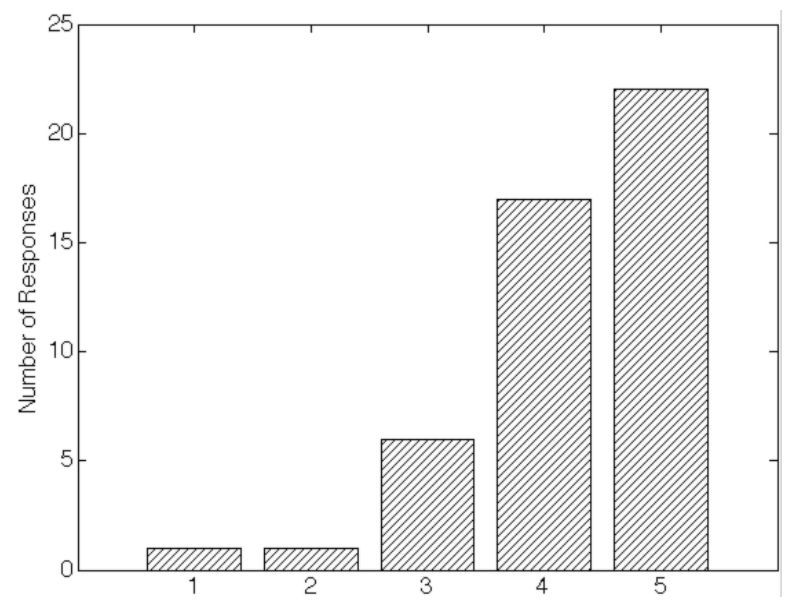

FIGURE 3. Histogram of responses to the prompt "When answering a question the lab instructors guided me to the thought process needed to answer the question rather then telling me the answer."

even when facilitating inquiry rather than supplying direct answers, as indicated by the prior question.

Prompts 5, 6, and 7 investigated students' perceptions of the relative effectiveness and value of undergraduate LAs as compared to a faculty instructor. Figure 5 shows response counts for prompt 5, "The lab instructors were able to relate to me on a level that most professors don't." It suggests that many students might see some benefit to having near-peers on hand to act as sympathetic mentors, perhaps with fresher memories of their own difficulties and insights, and perhaps better able to communicate with students on their own terms. (Note that we are speculating on the interpretation of this data; the prompt itself does not even indicate whether relating "on a level that most professors don't" is necessarily a good thing.)

Prompt 6 is fairly direct: "Having undergraduate lab instructors allowed me to learn more than I would have from a professor." The responses shown in Fig. 6 indicate that the majority of students are either neutral

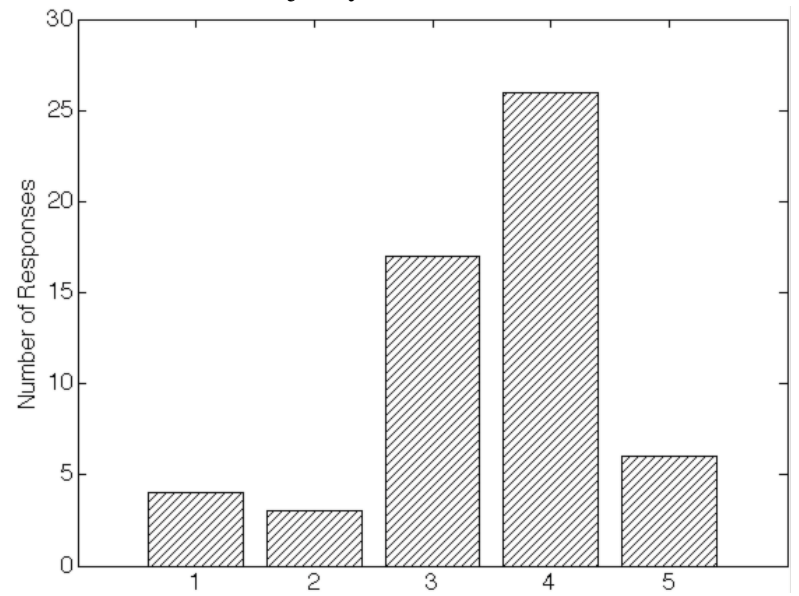

FIGURE 5. Histogram of responses to the prompt "The lab instructors were able to relate to me on a level that most professors don't."

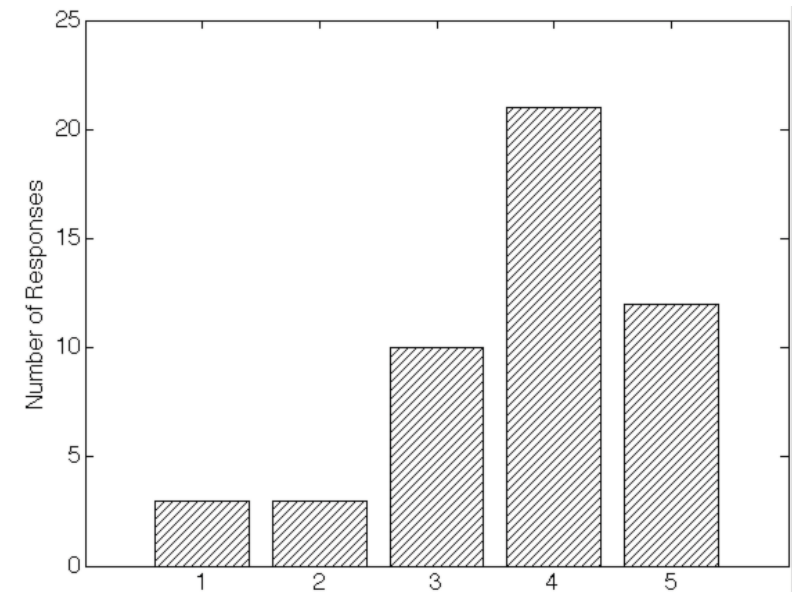

FIGURE 4. Histogram of responses to the prompt "The lab instructors were able to clear up points of confusion when asked."

on or in disagreement with this, with the most popular response being neutral. Note that even strong disagreement does not indicate that the respondent feels he or she learned less; it only means he or she did not learn more. To help disambiguate this, Prompt 7 asks the opposite: "The relationship with the lab instructors caused me to learn less than if they [sic] had a more traditional teacher." (We noticed the typographical error after the survey was conducted.) Figure 7 shows that the majority of students were neutral on or in disagreement with this statement. The results for prompts 6 and 7 together thus suggest that in general, students did not think that the use of undergraduate LAs either increased or decreased their learning.

However, the alternate wording of prompt 7 makes interpretation difficult by introducing possible conflating factors. It focuses the respondent on his or her relationships with the LAs rather than on their undergraduate status, potentially foregrounding idiosyncratic personality issues. Also, the respondent could interpret the

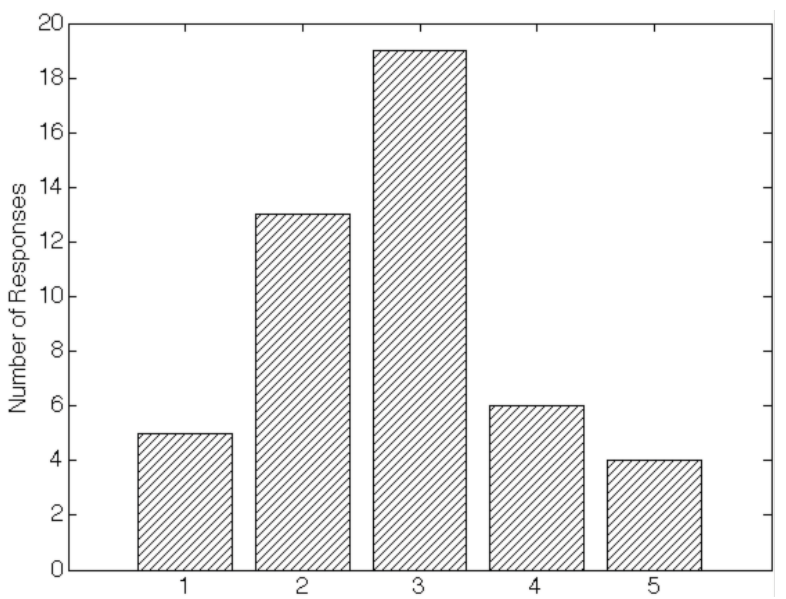

FIGURE 6. Histogram of responses to the prompt "Having undergraduate lab instructors allowed me to learn more than I would have from a professor." 


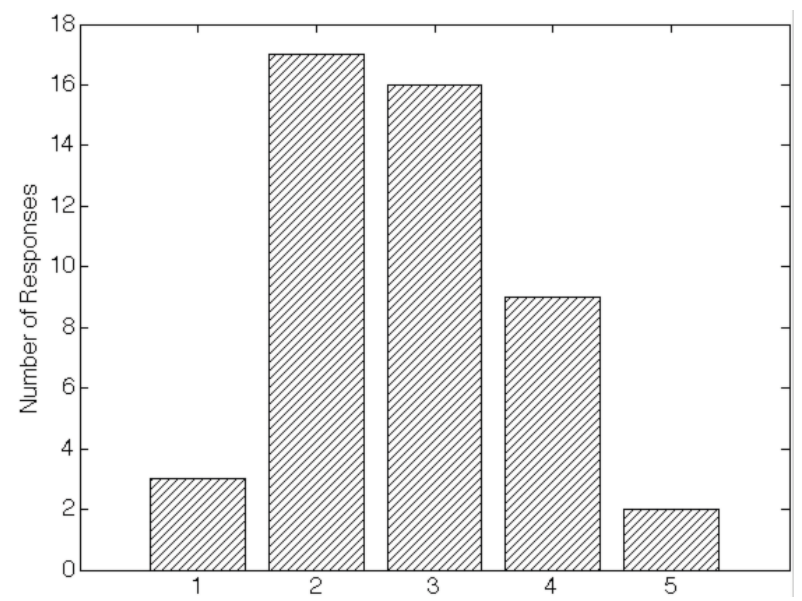

FIGURE 7. Histogram of responses to the prompt "The relationship with the lab instructors caused me to learn less than if they had a more traditional teacher."

term "traditional teacher" to mean graduate teaching assistants as well as faculty, or as referring to any teacher (including an undergraduate) employing traditional pedagogy rather than the active-learning, inquiry-focused approach of this course. Our interpretation of these results must therefore be quite tentative.

Most respondents left the "other comments" box blank. Four included a generic positive response, such as "Thanks!!" and "I really enjoyed it. They were very willing to help me in and out of lab." Two were generic and negative: "Teachers should teach labs," and "Wasn't too bad, just didn't seem professional." Four referred to how LAs responded to questions by trying to help students reach their own answers, one positively and three negatively; for example, "Too generic when trying to answer questions," "They were helpful about answering questions...," and "When I'm confused answering a question with another question does not [triple underline] work." One criticized grading practices: "Not very uniform. Different grading and instructions for different TA's." Finally, two criticized aspects of the curriculum design largely beyond the LAs' control, such as a perceived lack of connection between lab and lecture or inadequate time on a particular topic.

From these comments, we cannot draw strong conclusions about students' perceptions of their LAs, since we do not have any basis for comparison with the comments students might make about a faculty or graduate instructor.

\section{CONCLUSIONS AND DISCUSSION}

Overall, the data suggest that students in this course generally found their undergraduate LAs to be competent lab instructors with adequate content knowledge, a pedagogically sound and helpful interaction style, and an ability to relate to students in ways faculty typically can't or don't. Despite this, we see some indication that students at least suspect they might have learned more from a faculty instructor-a reasonable assumption, perhaps, despite the fact that many have never taken another physics lab and have no basis for comparison.

This, in conjunction with the "Wasn't too bad, just didn't seem professional" comment, raises the interesting research question of whether students might hold undergraduate instructors to different standards than graduate or faculty ones, perhaps giving undergraduates less benefit of the doubt. An important variable to attend to in a LA program may be the LAs' appearance of professionalism and competence; perhaps LAs should (or should deliberately not) be more attentive to signaling their professionalism, seriousness, and authority in the classroom.

While this study has examined students' reactions to undergraduate LAs in the aggregate, the students taking introductory physics are certainly not identical, and the spread of responses to this survey instrument undoubtedly hides a great deal of variability and nuance in students' reactions and opinions. We see a need for follow-up research using qualitative case study methods [6], in which we observe and interview a subset of students extensively in order to form a more complete picture of their laboratory experiences and perceptions. Such research could tease out this nuance and help us better understand how to shape our LA programs and mentor our LAs. Additionally, subsequent research should develop and validate a better survey instrument. The questionnaire used here, while adequate for this very preliminary investigation, has flaws in design and wording that limit our ability to draw strong conclusions.

Nevertheless, this study has reached a simple but very important conclusion that was not obvious a priori: It is demonstrably possible to implement an "extreme" LA program, in which undergraduates take on many of the responsibilities of instructors and handle almost all lab interaction, in such a way that students are generally satisfied with the quality of instruction they have received.

\section{REFERENCES}

1. V. Otero, S. Pollock and N. Finkelstein, Am. J. Phys. 78(11), 1218-1224 (2010).

2. J. E. Groccia and J. E. Miller, Innovative Higher Ed. 21(2), 87-100 (1996).

3. K. E. Gray, D. C. Webb, and V. K. Otero, AIP Conference Proceedings 1413 199-202 (2012).

4. V. Otero, N. Finkelstein, R. McCray and S. Pollock, Science 313, 445-446 (2006).

5. L. A. Harris, I. D. Beatty, and W. J. Gerace (this volume).

6. R. E. Stake, The Art of Case Study Research (Sage Publications, Thousand Oaks, 1995). 